\title{
Electrocatalytic reduction of 2, 2, 2-trichloro-1, 1-bis (4-chlorophenyl) ethanol (dicofol) in acetonitrile-aqueous solution using cyanocobalamin as a catalyst
}

\author{
Wanjau Tabitha Wangui ${ }^{1,}$, Geoffrey Njuguna Kamau ${ }^{2}$, Mwaniki Silas Ngari ${ }^{3}$, \\ Muya Catherine $\mathrm{Njambi}^{4}$ \\ ${ }^{1}$ Kisii University, School of Health Sciences, P.O. Box 408-40200 Kisii, Kenya \\ ${ }^{2}$ School of Physical Sciences, University of Nairobi, P.O. Box 30197 Nairobi, Kenya \\ ${ }^{3}$ Faculty of Science, Egerton University, Department of Chemistry, P.O. Box, 536 Njoro, Kenya \\ ${ }^{4}$ Faculty of Environmental Science, Technical University of Kenya, P.O. Box Nairobi, Kenya

\section{Email address:} \\ tabbymugo@gmail.com (W. T. Wangui),gnkamau@uonbi.ac.ke (G. N. Kamau), msngari@yahoo.com (Mwaniki S. N.), \\ muyacatenjambi@yahoo.com (M. C. Njambi)
}

\section{To cite this article:}

Wanjau Tabitha Wangui, Geoffrey Njuguna Kamau, Mwaniki Silas Ngari, Muya Catherine Njambi. Electrocatalytic Reduction of 2, 2, 2-Trichloro-1, 1-Bis (4-Chlorophenyl) Ethanol (Dicofol) in Acetonitrile-Aqueous Solution Using Cyanocobalamin as a Catalyst. Science Journal of Chemistry. Vol. 3, No. 1, 2015, pp. 1-10. doi: 10.11648/j.sjc.20150301.11

\begin{abstract}
This paper reports on the catalytic behaviour of cyanocobalamin $\left(\mathrm{VB}_{12}\right)$ towards the reduction of polyhalogenated organic pollutant 2, 2, 2-trichloro-1,1-bis (4-chlorophenyl) ethanol (dicofol) in acetonitrile-aqueous solution containing $0.1 \mathrm{M}$ $\mathrm{KNO}_{3}$ supporting electrolyte. Dicofol is a persistent, toxic organochlorine acaricide used in agriculture and horticulture to control spider mites and soft-bodied mites. Due to the chronic toxicity, bioaccumulation and carcinogenity, determination of persistent organochlorine pesticides like dicofol has become very important. The available methods are disfavored as they lack necessary simplicity, inexpensiveness and environmentally friendliness for routine analysis, and consequently, electrochemical methods have shown to be possible alternatives. Cyanocobalamin being one of the most nucleophilic species known in aqueous solution can undergo nucleophilic reactions which are efficient for dehalogenation of various organic halides. Direct reduction of cyanocobalamin exhibited a quasi-reversible two-electron reduction with the oxidation state of the central cobalt species going from +3 to +1 and $\mathrm{E}_{1 / 2}$ of $0.696 \pm 0.009 \mathrm{~V}$. Dicofol exhibited a single two-electron reduction peak at $-1.182 \pm 0.029 \mathrm{~V}$ vs $\mathrm{SCE}$. The $\mathrm{E}_{1 / 2}$ was $-1.074 \mathrm{~V}$ and the diffusion coefficient was $2.21 \times 10^{-5} \mathrm{~cm}^{2} \mathrm{~s}^{-1}$. Addition of dicofol to solution of cyanocobalamin resulted in a large reduction peak at around the reduction peak potential of cyanocobalamin $(-0.732 \pm 0.018 \mathrm{~V}$ versus SCE for six scan rates). This makes it clear that when cyanocobalamin is adsorbed on pyrolytic graphite electrode, it causes the lowering of overpotential for the reductive decomposition of dicofol by approximately $0.45 \mathrm{~V}$ and therefore $\Delta \mathrm{G}$ was about $1 \frac{1}{2}$ times lowered. The decrease in $\Delta \mathrm{G}$ implies that electrocatalysis is more kinetically favourable compared to direct electrochemical activation of carbon-halogen bonds.
\end{abstract}

Keywords: Catalytic Activity, Current Density, Current Efficiency, Cyanocobalamin, Dicofol, Diffusion Coefficient, Electrocatalysis, Pesticides, Pollutants

\section{Introduction}

Organochlorine pesticides are a class of particular concern because of ubiquitous presence in the environment and their persistent nature [1]. Dicofol is an acaricide used in apples, pears, soft fruit, cucumbers, tomatoes, hops, vines, lettuce and ornamentals. It has a chemical formula $\mathrm{C}_{14} \mathrm{H}_{9} \mathrm{Cl}_{5} \mathrm{O}$ and Its chemical name is 2,2,2-Trichloro-1,1-bis(4-chlorophenyl) ethanol. It differs from DDT by the replacement of the hydrogen $(\mathrm{H})$ on $\mathrm{C}-1$ by a hydroxyl $(\mathrm{OH})$ functional group.<smiles>OC(c1ccc(Cl)cc1)(c1ccc(Cl)cc1)C(Cl)(Cl)Cl</smiles>

Figure 1. Dicofol Structural Formula. 
It first appeared in the scientific literature in 1956, and is sold under a number of trade names, including Hilfol, Kelthane, Acarin, Cekudifol, Decofol, Dicomite, Difol, Dicaron, Mitigan among others. It is produced as emulsifiable concentrate and wettable powder formulations [2]. The EPA has classified dicofol as toxicity class II - moderately toxic, and toxicity class III - slightly toxic, depending on the formulation. Products containing dicofol bear the Signal Word WARNING or CAUTION, depending on the formulation [3].

Exposure of the public to dicofol through foods such as pears, blackcurrents and strawberries can be higher than expected and may result in a breach of the ADI (acceptable daily intake) [4]. Dicofol had moderate acute oral toxicity. It produces signs of toxicity consistent with central nervous system depression. WHO has classified dicofol as slightly hazardous [5].

The USEPA's PBT (persistence, bioaccumulation, toxicity) profiling model predicts dicofol to be persistent and bioaccumulative [6]. Environmental concerns were raised about the potential of dicofol for bioaccumulation in aquatic species and the long-term risk to birds and mammals. It can be stored in fatty tissues after which intense activity or starvation may mobilize it, resulting in the reappearance of toxic symptoms long after actual exposure [7].

Dicofol in soil is expected to bind to organic matter and is not likely to leach to groundwater, although there are reports of dicofol in groundwater. However, residues in soil decrease rapidly. Dicofol is practically insoluble in water. Levels in drinking-water would be expected to be very low. In surface water, it is expected to adsorb to sediment and can hydrolyse to dichlorobenzophenone [6]. In a number of studies, dicofol residues on treated plant tissues have been shown to remain unchanged for up to 2 years [7].

The decomposition of organohalides emissions to air, water and land by the selective removal of the halogen group represents a valid treatment route, which, although not leading to the complete mineralization of the pollutants, produces less harmful products [8]. It is well known that the injection of one electron into an organic halide, by reaction with homogeneous electron donors as well as by electrochemical or other means, leads to the fragmentation of the carbon-halogen bond. During the reductive cleavage of a carbon-halogen bond, electron transfer (ET) and bond breaking may occur either in a single step or in two distinct steps [9].

Aliphatic and aromatic organohalide molecules (RX) can be directly reduced at electrodes by a pathway represented conceptually by scheme I where the source of electrons is a cathode in an electrochemical reactor.

Scheme I

$$
\text { 1. } \mathrm{RX}+\mathrm{e}-\rightarrow(\mathrm{RX} \cdot-) \rightarrow \mathrm{R} \cdot+\mathrm{X}-
$$$$
\text { 2. } \mathrm{R} \cdot+(\mathrm{e}-, \mathrm{H}+) \rightarrow \mathrm{RH}
$$

The halogen atoms $(\mathrm{X})$ are replaced with hydrogen, yielding a hydrocarbon $\mathrm{RH}$ which is less toxic than its parent RX. Pesticides that break down quickly generally do not persist in the environment or on the crop. However, pesticides that break down too rapidly may only provide short-term control. Depending on their fate, they may be degraded to harmless by-products or they may exert harmful effects through toxicity, biomagnifications, and/or persistence in the environment [10]. Examples of some of the products obtained from organohalide pollutants are shown in the table below [12].

Table 1. Hydrocarbon products from electrocatalytic reduction of organohalide pollutants.

\begin{tabular}{ll}
\hline Pollutant & Product \\
\hline $\begin{array}{l}\text { AlkylVicinal } \\
\text { polyhalides }\end{array}$ & Olefins (includes many organohalide pesticides) \\
Polychlorophenols & Phenol \\
$\begin{array}{l}\text { Polychlorobenzenes } \\
\text { Polychlorinated }\end{array}$ & Benzene \\
biphenyls & Biphenyl \\
Polyhaloacetic acid & Acetic acid \\
DDT & Diphenylmethylmethane \\
\hline
\end{tabular}

For alkyl halides the intermediate $\mathrm{RX}^{--}$is not detected and Eqn (1) is a single concerted process leading to the radical $\mathrm{R}^{\circ}$ and a halide ion. For aryl halides, the reaction proceeds through a detectable intermediate anion radical $\mathrm{RX}^{--}$so that eqn. (1) represent two elementary reaction steps. However, the process requires very negative electrode potentials [11]. Thus, much attention has been devoted to develop electrocatalytic processes, either by utilizing homogeneous redox catalysts, such as metal complexes or aromatic mediators, or by the use of electrocatalytic cathodic materials [9].

An alternative to direct electrochemical reduction is thus electrochemical catalysis that uses mediators (catalysts) to shuttle electron between molecules and electrodes at less negative voltage. This lowers the applied potential needed to reduce or oxidize recalcitrant substrate. Catalytic reduction usually features a bimolecular rate-determining reaction between reduced mediator and substrate [11].

The electro-reduction process is analysed and discussed in terms of electrode material, reaction medium, cell design and operation, and of substrate classification [8]. The reaction occurs at the electrode potential $\mathrm{E}^{\circ}$ at which the active form of the catalyst is produced. The rate determining step involves reaction of activated catalyst and reactant [13].

Mass transfer is movement of material from one location to another in solution. In electrochemical systems, three modes of mass transport are generally considered including diffusion, convection and migration. Diffusion removes concentration gradients by the movement of material from a high concentration to low concentration. Migration is movement of charged species due to a potential gradient. Electrolysis is carried out with a large excess of inert electrolyte in the solution so the current of electrons through the external circuit can be balanced by the passage of ions through the solution between the electrodes, and a minimal amount of the electroactive species will be transported by migration. Convection is the movement of species due to mechanical forces and usually can be eliminated [14], [15].

In this work cyanocobalamin is used as the catalyst. It is a collection of cobalt and corrin ring molecules which are defined by their particular vitamin function in the body (figure 2) [13]. 


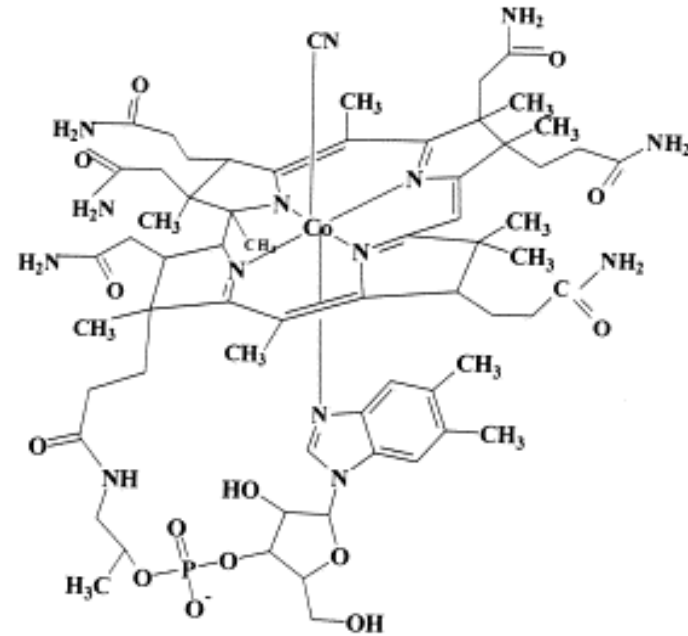

Figure 2. Molecular structure of cyanocobalamin.

In the cobalamins, cobalt normally exists in the trivalent state, $\mathrm{Co}$ (III). However, under reducing conditions, the cobalt center is reduced to $\mathrm{Co}(\mathrm{II})$ or even $\mathrm{Co}(\mathrm{I})$, which are usually denoted as $B_{12 r}$ and $B_{12 s}$, for reduced and super reduced, respectively. Both $B_{12 \mathrm{r}}$ and $\mathrm{B}_{12 \mathrm{~s}}$ are stable indefinitely under oxygen-free conditions. $\mathrm{B}_{12 \mathrm{r}}$ appears orange-brown in solution, while $\mathrm{B}_{12 \mathrm{~s}}$ appears bluish-green under natural daylight, and purple under artificial light [13].

$\mathrm{B}_{12 \mathrm{~s}}$ is often referred to as a "supernucleophile". This property allows the convenient preparation of cobalamin analogs with different substituents, via nucleophilic attack on alky halides and vinyl halides [16]. We report in this work on the electrocatalytic properties of cyanocobalamin towards dehalogenation of dicofol.

\section{Experimental}

Cyclic voltammetry (CV) technique was used to study electrochemical reaction mechanisms that give rise to electroanalytical current signals. The experiment demonstrates the determination of the formal reduction potential (E0'); the number of electrons transferred in the redox process (n); the diffusion coefficient (D); electrochemical reversibility; and the effects of varying concentration (C) and scan rate (v). In this experiment, the basics of cyclic voltammetry were illustrated by looking at the one-electron reduction of ferricyanide to ferrocyanide. The properties of the reaction:

$$
\left[\mathrm{Fe}^{\mathrm{III}}(\mathrm{CN})_{6}\right]^{3-}+\mathrm{e}^{-} \rightleftharpoons\left[\mathrm{Fe}^{\mathrm{II}}(\mathrm{CN})_{6}\right]^{4-}
$$

were investigated in order to validate the instrument.

\subsection{Reagents}

A $250 \mathrm{~mL}$ stock solution of $0.01 \mathrm{M} \mathrm{K} \mathrm{K}_{3} \mathrm{Fe}(\mathrm{CN})_{6}$ in $0.1 \mathrm{M}$ $\mathrm{KNO}_{3}$ (supporting electrolyte) was prepared. Dilutions of this solution were performed to give solutions of $1,2,3,4$, and $5 \mathrm{mM} \mathrm{K}_{3} \mathrm{Fe}(\mathrm{CN})_{6}$ in $0.1 \mathrm{M} \mathrm{KNO}_{3}$. The procedure was repeated for $0.001 \mathrm{M}, 0.0001 \mathrm{M}$ cyanocobalamin and some organohalide pesticides including $0.001 \mathrm{M}$ dicofol in acetonitrile-water (1:1) as the solvent media.

\subsection{Apparatus}

In this experiment, a computer-controlled potentiostat; Autolab PGSTAT12 electrochemical analyzer; Princeton Applied Research, PAR; 174A) running General Purpose electrochemical system (GPES) software was used. Layout of a three-electrode glass cell was used together with a pyrolitic graphite working electrode $\left(5.0 \mathrm{~mm}\right.$ diameter; $\left.0.1963 \mathrm{~cm}^{2}\right)$, Standard Calomel reference electrode (SCE) and a platinum wire auxiliary electrode. All experiments were done at room temperature $\left(25 \pm 1^{\circ} \mathrm{C}\right)$.

\subsection{Procedure}

The working electrode was polished using alumina slurry on soft lapping pads prior to experimentation in order to have new working surface. Each solution prepared above was added to the cell and thoroughly purged with oxygen-free nitrogen (BOC Gases) for 10 minutes before running $\mathrm{CV}$ (Oxygen is known to interact with $\mathrm{Co}$ (II) and $\mathrm{Co}(\mathrm{I})$ species). In addition, the solution was stirred between experiments in order to restore initial conditions, but it was not stirred during the experiment. $\mathrm{KNO}_{3}$ supporting electrolyte was to prevent charged electroactive species from migrating in the electric field gradient. This ensured diffusion controlled electrode process. Direct reduction potentials of individual organohalides and the catalyst were determined prior to electrocatalysed reduction since the catalysts chosen are those that accept electrons rapidly and reversibly from the cathode at a less negative voltage than does $\mathrm{RX}$, decreasing the required input of electrical power,

\section{Results and Discussion}

\subsection{Ferricyanide}

$\mathrm{Fe}^{3+} / \mathrm{Fe}^{2+}$ couple exhibited fast electron transfer kinetics with a reversible electrode reaction without any complications of proceeding or post chemical reactions (figure 3 ).

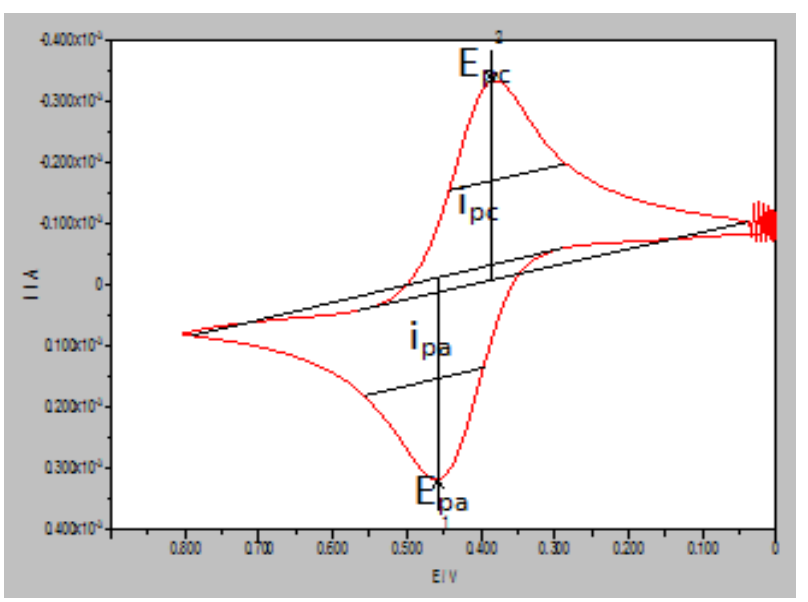

Figure 3. Cyclic voltammogram for the reduction of $0.01 \mathrm{M}$ ferricyanide in 0.1 $\mathrm{M} \mathrm{KNO}_{3}$ on a $0.1963 \mathrm{~cm}^{2}$ pyrolytic graphite electrode. Scan rate is $0.01 \mathrm{~V} / \mathrm{s}$. 
The peak shape of the reductive and reverse oxidative current versus electrode potential curve (I-E) in figure 3 is typical of an electrode reaction in which the rate is governed by diffusion of the electroactive species to a planar electrode surface. That is, the rate of the electron transfer step is fast compared to the rate at which ferricyanide diffuses from the bulk solution to the electrode surface due to a concentration gradient, as ferricyanide is reduced to ferrocyanide.

The important parameters obtained from a cyclic voltammogram are the anodic and cathodic peak currents (ipa and ipc) and the anodic and cathodic peak potentials (Epa and Epc). The peak current for a reversible process is given by the Randles-Sevick equation:

$$
\mathrm{i}_{\mathrm{p}}=\left(2.69 \times 10^{5}\right) \mathrm{n}^{3 / 2} \mathrm{ACD}^{1 / 2} \mathrm{~V}^{1 / 2}
$$

where the constant $\mathrm{k}=2.69 \times 105 ; \mathrm{n}$ is the number of moles of electrons transferred per mole of electroactive species (e.g., ferricyanide); $\mathrm{A}$ is the area of the electrode in $\mathrm{cm} 2$; $\mathrm{D}$ is the diffusion coefficient in $\mathrm{cm} 2 / \mathrm{s} ; \mathrm{C}$ is the solution concentration in mole/L; and $\mathrm{V}$ is the scan rate of the potential in volt/s. The $i_{p}$ is linearly proportional to the $\mathrm{V}^{1 / 2}$ for diffusion controlled electrode process (figure 4).

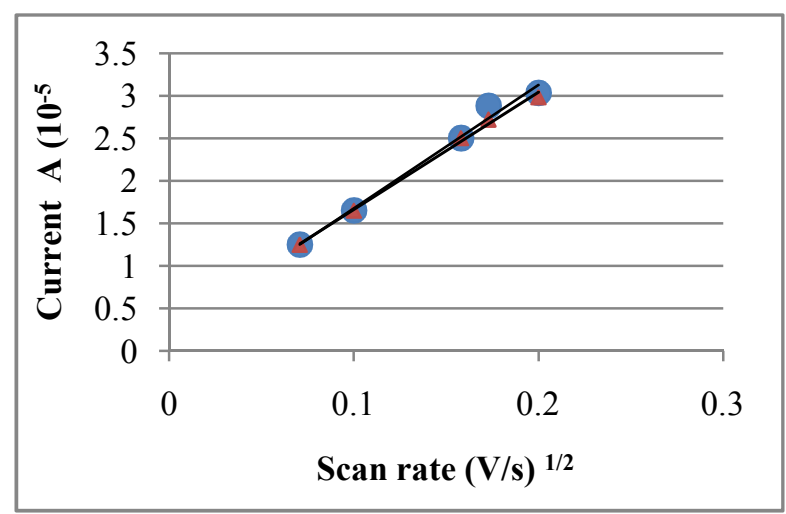

Figure 4. Voltammetric peak current dependence on scan rate. Cathodic peak current is represented by red data markers and anodic peak current is represented by blue data markers.

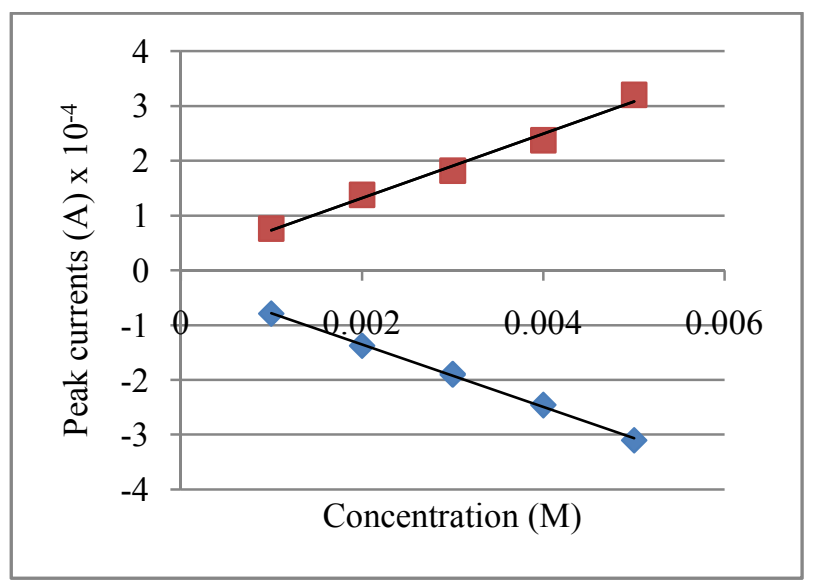

Figure 5. Peak current dependence on concentration. $a=$ cathodic peak currents; $b=$ anodic peak currents.

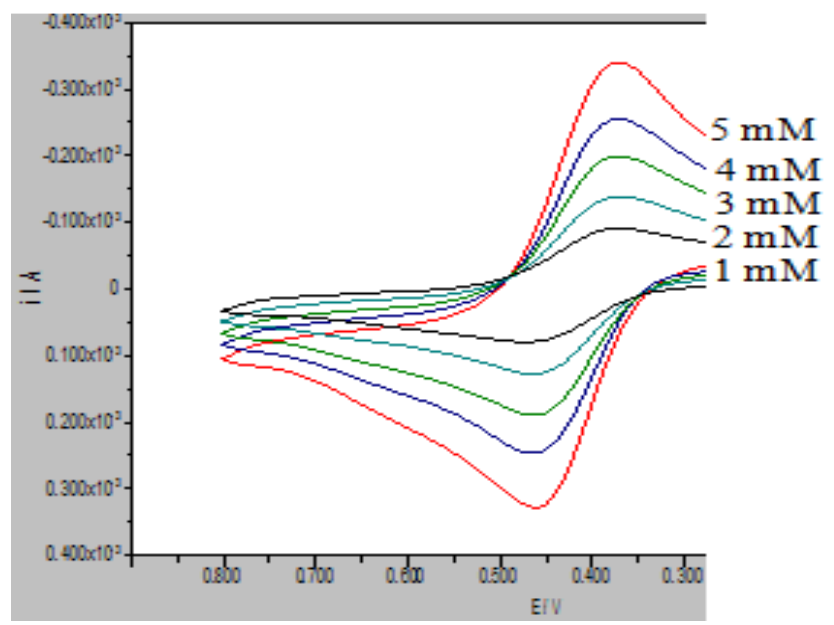

Figure 6. Influence of concentration on peak currents for ferricyanide solution.The peak current increases with increase in concentration (1mM $-5 m M)$.

The ratio of cathodic and anodic peak currents may also be used to determine reversibility of a redox reaction. For a reversible redox process ipc/ipa $=1$. The nearly identical slopes from the linear regression analysis of the cathodic and anodic peak currents in figure 4 indicate that the peak current ratio is approximately one. From Randle Sevcik-equaation, $i_{p}$ is also linearly proportional to the bulk concentration, $\mathrm{C}$, of the electroactive species (figures 5 and 6).

The calculated current density was $1.15 \pm 0.39 \mathrm{~A} / \mathrm{m}^{2}$. while the diffusion coefficients for ferricyanide and ferrocyanide were $7.55 \times 10^{-6} \mathrm{~cm}^{2} \mathrm{~s}^{-1}$ and $6.81 \times 10^{-6} \mathrm{~cm}^{2} \mathrm{~s}^{-1}$ respectively. This closely related to the literature value of $7.6 \times 10^{-6} \mathrm{~cm}^{2} \mathrm{~s}^{-1}$ and $6.3 \times 10-6 \mathrm{~cm}^{2} \mathrm{~s}-1$, respectively reported by [17]. Diffusion coefficient for ferricyanide also relates closely to $7.2 \times 10^{-6} \mathrm{~cm}^{2} \mathrm{~s}^{-1}$ and $7.26 \times 10^{-6} \mathrm{~cm}^{2} \mathrm{~s}^{-1}$ in $0.1 \mathrm{M} \mathrm{KCl}$ and $7.01 \times 10^{-6} \mathrm{~cm}^{2} \mathrm{~s}^{-1}$ in $0.1 \mathrm{M} \mathrm{KNO}_{3}$ reported by [18]. The difference in diffusion coefficients in different solvents is expected due to the difference in specific resistance of the media [19].

The type of supporting electrolyte affects the specific resistance of the solvent-supporting electrolyte solution, the electron transfer rate constant, the mass transfer phenomena, characteristic electron transfer and charge transfer coefficient. These parameters contribute directly to diffusion coefficient observed [20].

The formal redox potential (E0') for a reversible process is given by the mean of the peak potentials. This experiment gave an average approximation of $0.332 \pm 0.007 \mathrm{~V}$ which compares closely with $0.370 \mathrm{~V}$ formal redox potentials of ferricyanide/ferrocyanide couple in $100 \%$ water reported by Rao et al., 1978. The formal potential of the ferro-ferricyanide system varies strongly from acidic to strongly alkaline media. Popp and Mohai (1962) measured the redox potential of ferro-ferricyanide couple in presence of potassium compounds. They observed that the potential was highest $(0.495 \mathrm{~V})$ in $1.0 \mathrm{KOH}$ solution and lowest $(0.405 \mathrm{~V})$ in $\mathrm{K}_{3} \mathrm{PO}_{4}$ solution. Rock, 1966 obtained $\mathrm{E}^{\mathrm{o}^{\prime}}$ of $0.370 \pm 0.005 \mathrm{~V}$. Kolthoff and Tomsick (1935) made calculation of $\mathrm{E}^{0^{\prime}}$ value as $0.36 \mathrm{~V}$ 
[21].

The other characteristic potential parameter is the separation of the peak potentials $\Delta \mathrm{Ep}\left(\mathrm{E}_{\mathrm{pa}}-\mathrm{E}_{\mathrm{pc}}\right)$. The theoretical value for $\Delta \mathrm{Ep}$ for a reversible process is $0.057 / \mathrm{n} \mathrm{V}$, and it is independent of scan rate. The measured value for this experiment was $0.070 \pm 0.005 \mathrm{~V}$. This was expected due to uncompensated solution resistance and non-linear diffusion. Providing that the charge-transfer reaction is reversible, it then follows that there is no surface interaction between the electrode and the reagents, and that the redox products are stable. Larger values of $\Delta \mathrm{Ep}$, which increase with increasing scan rate, are characteristic of slow electron transfer kinetics. Scatter in data for this work is attributed to normal variance in electrode polishing [22]. Considering above preliminary studies, it was concluded that the procedure followed was appropriate for the current research.

\subsection{Cyanocobalamin}

Electrode reduction of $1.0 \times 10^{-4} \mathrm{M}$ and $1.0 \times 10^{-3} \mathrm{M}$ solutions of cyanocobalamin in acetonitrile-water (1:1) containing 0.1 $\mathrm{M} \mathrm{KNO}_{3}$ at a potential ranging from 0 to $-1.5 \mathrm{~V}$ (versus SCE) exhibited a pair of well-defined cyclic voltammetric peaks for the redox reaction (figure 6 and 9)

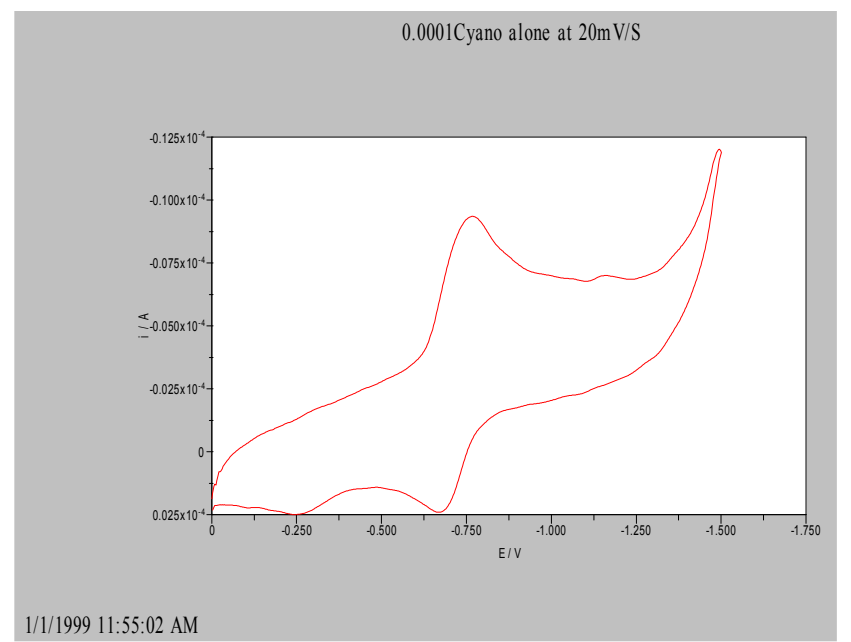

Figure 7. Cyclic voltammogram for $0.0001 \mathrm{M}$ cyanocobalamin in acetonitrile-aqueous solution (1:1) containing $0.1 \mathrm{M} \mathrm{KNO}_{3}$ at scan rate of $0.01 \mathrm{~V} / \mathrm{s}$ vs $S C E$.

The Epc for $1.0 \times 10-4 \mathrm{M}$ was about $-0.732 \pm 0.018 \mathrm{~V}$ for six scan rates and $-0.817 \mathrm{M} \pm 0.037 \mathrm{~V}$ for $1.0 \times 10^{-3} \mathrm{M}$ cyanocobalamin versus SCE for five scans which compared favourably with $-0.790 \mathrm{~V}$ reported previously [23]. The corresponding anodic peak is much smaller than the forward (cathodic) peak. The slight difference in peak potential shows its dependence on concentration. Using Nernst equation, $\mathrm{E}=\mathrm{E}^{0^{\prime}}-\frac{0.0591}{\mathrm{n}} \log \mathrm{Q}$, the number of electrons (n) involved in the process were found to be two. The reduction is therefore associated with one-step two-electron reduction of the CoIII center to CoI. This is exhibited by the linear plot of Eapp versus $\log [\mathrm{i} / \mathrm{ilim}-\mathrm{i}]$ (figure 9 ).

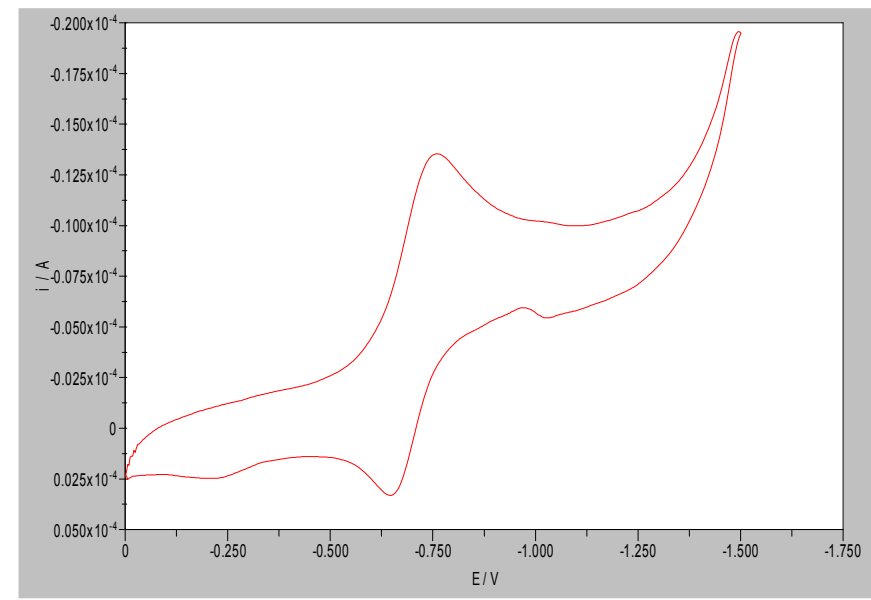

Figure 8. Cyclic voltammogram for $0.001 M$ cyanocobalamin in acetonitrile-aqueous solution (1:1) containing $0.1 \mathrm{M} \mathrm{KNO}_{3}$ at scan rate of $0.01 \mathrm{~V} / \mathrm{s}$ vs $S C E$.

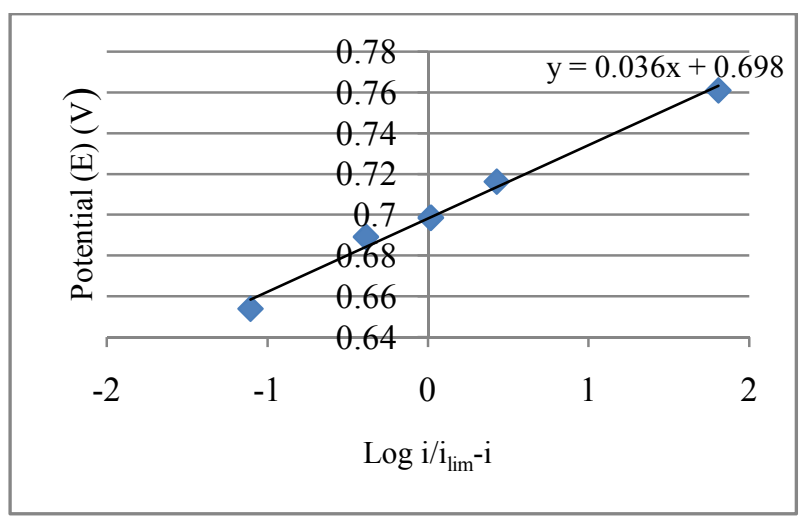

Figure 9. A Plot of applied potential (Eapp) against log [i/ilim-i] for cyanocobalamin in solutions of acetonitrile:water (1:1).

There have been reports of direct two-electron reduction of Co(III) to Co(I) on GCE [ 24], [25], [26] and one-electron reduction by some authors on a GCE and PG but using different electrolytes ([27], [23]. According to Lexa, et al., 1980 , the presence of strong axial ligands such as $\mathrm{CN}^{-}$induces large negative shifts of the $\mathrm{Co}^{\mathrm{III}} / \mathrm{Co}^{\mathrm{II}}$ reduction in cyanocobalamin, resulting in the merging of $\mathrm{Co}^{\mathrm{III}} / \mathrm{Co}^{\mathrm{II}}$ and $\mathrm{Co}^{\mathrm{II}} / \mathrm{Co}^{\mathrm{I}}$ reduction couples and a direct two-electron reduction of $\mathrm{Co}^{\mathrm{III}}$ to $\mathrm{Co}^{\mathrm{I}}$ [24].

The $E_{1 / 2}$ obtained from the $y$ intercept of the plot of $E_{\text {app }}$ versus $\log \left[\mathrm{i} / \mathrm{i}_{\lim }-\mathrm{i}\right]$ was $0.696 \pm 0.009 \mathrm{~V}$. This value is reported for the first time in this study. The cathodic-anodic peak separation $\left(\Delta \mathrm{E}_{\mathrm{p}}\right.$ was $103 \mathrm{mV}$ vs SCE. This is greater than the theoretical $59 \mathrm{mV}$ for a reversible reaction though as mentioned earlier, it is typically $70-100 \mathrm{mV}$. These larger differences or non-symmetric reduction and oxidation peaks like in the case of cyanocobalamin are an indication of a non-reversible reaction i.e a quasi-reversible process which is characterized by $\Delta \mathrm{Ep}>59 / \mathrm{n} \mathrm{mV}$, with the value increasing with increasing scan rates. This could be due to uncompensated solution resistance and non-linear diffusion, which is characteristic of slow electron transfer kinetics ([28], [29].

From the shape of the voltammogram, it is clear that the 
anodic to cathodic peak current ratio $\mathrm{I}_{\mathrm{pa}} / \mathrm{I}_{\mathrm{pc}} \neq 1$. This is associated with chemical reactions of $\mathrm{O}$ (oxidized species) and $\mathrm{R}$ (reduced species). Equilibrium values of $\mathrm{O}$ and $\mathrm{R}$ can only be maintained during a cyclic voltammetry experiment if both $\mathrm{O}$ and $\mathrm{R}$ are stable on the experimental time scale. e.g if the reduction of $\mathrm{O}$ to $\mathrm{R}$ is followed by the conversion of $\mathrm{R}$ to $\mathrm{P}$ (product), then more R must be generated to compensate for the loss of $\mathrm{R}$. Therefore, the rate of reduction increases and $\mathrm{E}_{\mathrm{pc}}$ moves to more positive value and Ipa/Ipc $\neq 1$ [28]. In addition, transition metals are known to shift in the geometry of the coordination sphere. Out of the three possible oxidation states of cyanocobalamin, the Co species is hexa-coordinate in the +3 oxidation state, penta-coordinate in the +2 state, and tetracoordinate when in the +1 oxidation state [30].

The peak current, $i_{p}$ was proportional to the square root of scan rate, $v^{1 / 2}$ indicating diffusion controlled electrode process (figure 10).

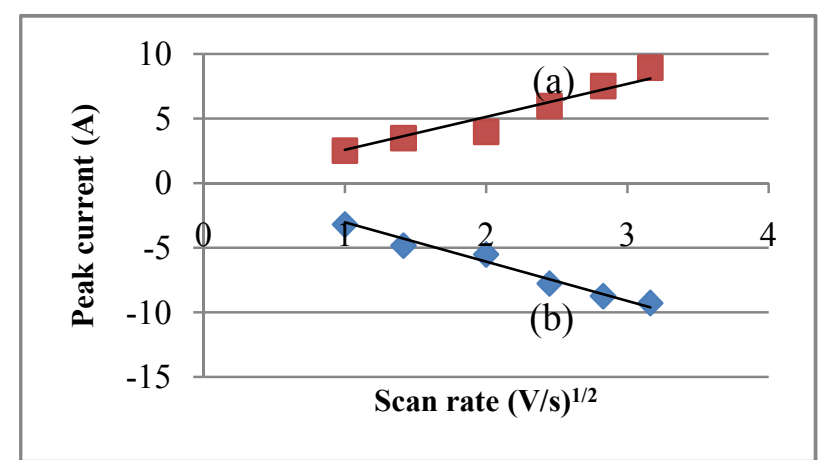

Figure 10. A plot of peak currents (A) versus square root of scan rate $(\mathrm{V} / \mathrm{s})$ for $0.0001 M$ cyanocobalamin in acetonitrile/water. $a=$ anodic peak currents $b=$ cathodic peak currents.

Diffusion coefficient calculated using Randle-Sevcik relationship yielded $1.06 \times 10^{-7} \mathrm{~cm}^{2} \mathrm{~s}^{-1}$. This value falls between what is reported in aqueous solutions $\left(1.4 \times 10^{-6}\right.$ $\left.\mathrm{cm}^{2} \mathrm{~s}^{-1}\right)$ and in ionic media $\left(0.9 \times 10^{-9} \mathrm{~cm}^{2} \mathrm{~s}^{-1}\right)$ [26]. As mentioned earlier difference in diffusion coefficients in different solvents is expected due to the difference in specific resistance of the media [19].

\subsection{Organohalide Pesticides}

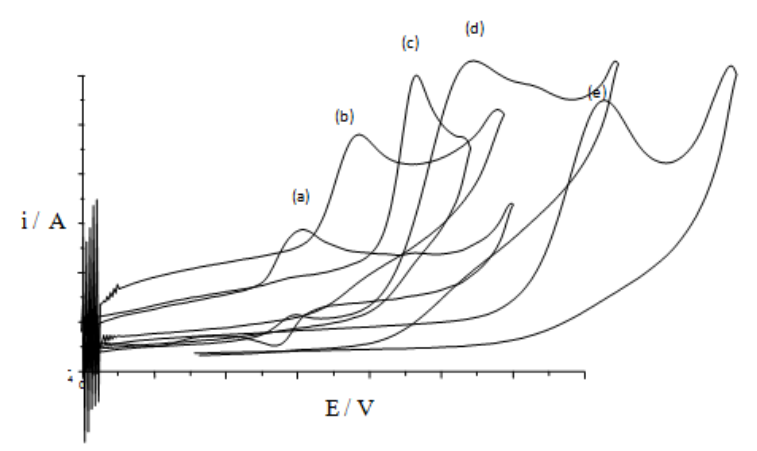

Figure 11. An overlay of cyclic voltammograms for $0.0001 \mathrm{M}$ cyanocobalamin (a), DDE (b), dicofol (c), captan (d) and Methoxychlor (e) in acetonitrile/water at $0.01 \mathrm{~V} / \mathrm{s}$ vs SCE.

Direct reduction of a number of organohalides in acetonitrile-water (1:1) containing $0.1 \mathrm{M} \mathrm{KNO}_{3}$ was studied without added cyanocobalamin before narrowing down to dicofol. The cathodic sweep at a scan rate of $0.01 \mathrm{~V} / \mathrm{s}$ shows a single cathodic wave at $-1.512 \mathrm{~V}$. for aldrin, $-1.339 \mathrm{~V}$ for methoxychlor, $-1.250 \mathrm{~V}$ for DDE, $-1.275 \mathrm{~V}$ for captan and two reduction peaks for diquatdibromide (figures 12 and 13).

The reduction peak potentials for all the investigated organohalides are more negative than for cyanocobalamin. However, one of the two reduction peaks for diquat dibromide is at a less negative potential than cyanocobalamin. This implies that cyanocobalamin is an appropriate catalyst for these organohalides except diquat dibromide.

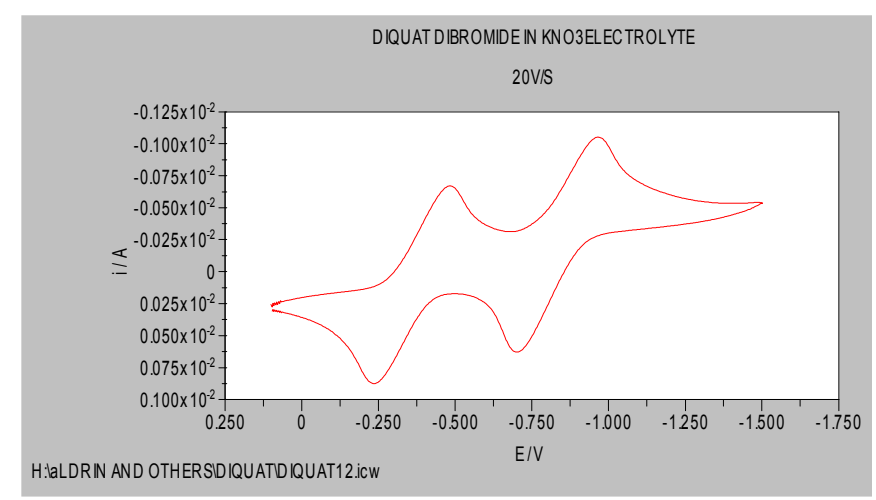

Figure 12. $\mathrm{CV}$ for $0.1 \mathrm{mM}$ diquat dibromide in presence of $0.0001 \mathrm{M}$ cyanocobalamin in acetonitrile/water (1:1) solution containing $0.1 \mathrm{M} \mathrm{KNO} \mathrm{N}_{3}$ at $0.02 \mathrm{~V} / \mathrm{s}$ vs $S C E$

\subsection{Dicofol}

Direct reduction of $1 \times 10^{-3} \mathrm{M}$ dicofol in acetonitrile-water (1:1) containing $0.1 \mathrm{M} \mathrm{KNO}_{3}$ was studied without added cyanocobalamin (figure 13). The voltammogram showed an irreversible reduction process as expected for most pesticides.

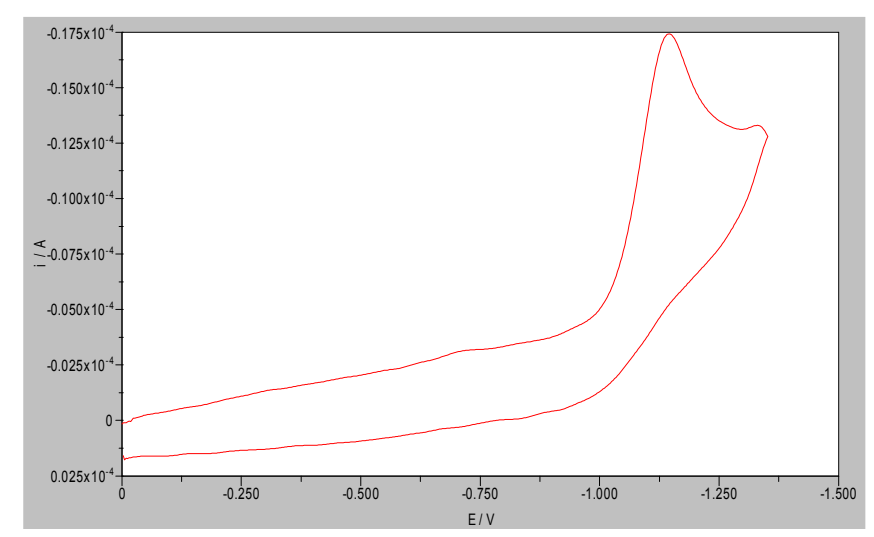

Figure 13. Voltammogram for $1.0 \times 10^{-3} \mathrm{M}$ dicofol in acetonitrile: water (1:1) containing $0.1 \mathrm{M} \mathrm{KNO}_{3}$ at $0.01 \mathrm{~V} / \mathrm{s}$.

A reduction peak at $-1.182 \pm 0.029 \mathrm{~V}$ versus SCE for six scan rates was observed. This compared favourably with $-1.324 \mathrm{~V}$ versus SCE obtained for $0.99 \mathrm{mmol}$ at $0.1 \mathrm{~V} / \mathrm{s}$ ([31]. Dicofol showed no peak for the oxidation process. Absence of anodic peaks in the reverse scan is an indication of an irreversible electrode process. The product of reduction is unstable and not much of it goes through oxidation [12]. It could also mean that 
at least the unpaired electron on the free radical is strongly bound. Dicofol exhibited a linear plot of $E_{\text {app }}$ vs $\log \left[\mathrm{i} / \mathrm{i}_{\mathrm{d}} \mathrm{i}\right]$ yielding a value of $n=2$ (figure 14 ).

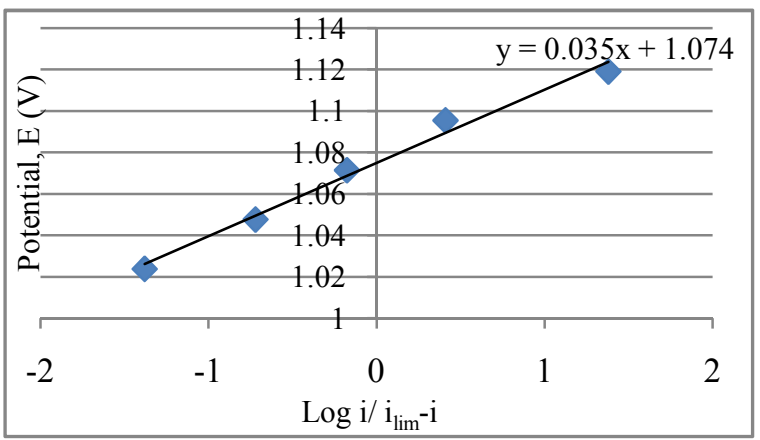

Figure 14. A Plot of applied potential (Eapp) against log [i/ilim-i] for dicofol.

The number of electrons $(n=2)$ involved in the process agrees with the reports by Abdirisak, 2009 concerning the aromatic chlorides. As mentioned earlier, the injection of one electron into the organic halide like dicofol leads to the fragmentation of the carbon halogen $\sigma$ bond. There are two possible mechanisms for such reductive cleavages according to Abdirisak, et al., 2009. Electron transfer (ET) and bond breaking can occur in a stepwise manner with the intermediate formation of radical anion (equation i) or in a concerted way in which the two fragments, the organic radical and the halide leaving ion, are produced in a single step (equation ii).

$$
\begin{aligned}
& R X+e^{-} \leftrightarrow R X^{\bullet-} \rightarrow R^{\bullet}+X^{-} \\
& R X+e^{-} \rightarrow R^{\bullet}+X^{-}
\end{aligned}
$$

It is well recognised that aromatic chlorides undergo a dissociative electron transfer due to their low lying $\pi^{*}$ orbitals in which the incoming electron is accomodated [11]. Since the aromatic radical produced by the rupture of the bond, is more easily reducible than the starting halide, often the first reduction peak corresponds to a two-electron process leading to the formation of the chloride ion and a carbanion, which is protonated by any proton donor (HA) present in solution [32]. The expected protonation reaction is as follows:

$$
\mathrm{R}^{-}+\mathrm{HA} \rightarrow \mathrm{RH}+\mathrm{A}^{-} \text {. }
$$

The $E_{1 / 2}$ obtained from the $y$ intercept of the plot of $E_{\text {app }}$ versus $\log \left[\mathrm{i} / \mathrm{i}_{\lim }-\mathrm{i}\right]$ was $-1.074 \mathrm{~V}$. This value is reported for the first time in this study. Peak current $I_{p c}$ was proportional to square root of scan rate indicating a diffusion controlled process with a diffusion coefficient of $2.21 \times 10^{-5} \mathrm{~cm}^{2} \mathrm{~s}^{-1}$, also reported for the first time.

\subsection{Electrocatalysis of Dicofol in Presence of Cyanocobalamin}

Figure 15 shows an overlay of the direct reduction of cyanocobalamin and dicofol. The fact that cyanocobalamin is reduced at potentials centred around $0.732 \pm 0.018 \mathrm{~V}$ and dicofol around $-1.182 \pm 0.029 \mathrm{~V}$ suggests that it could provide catalytic effects with significant lowering of potentials for reduction of dicofol.

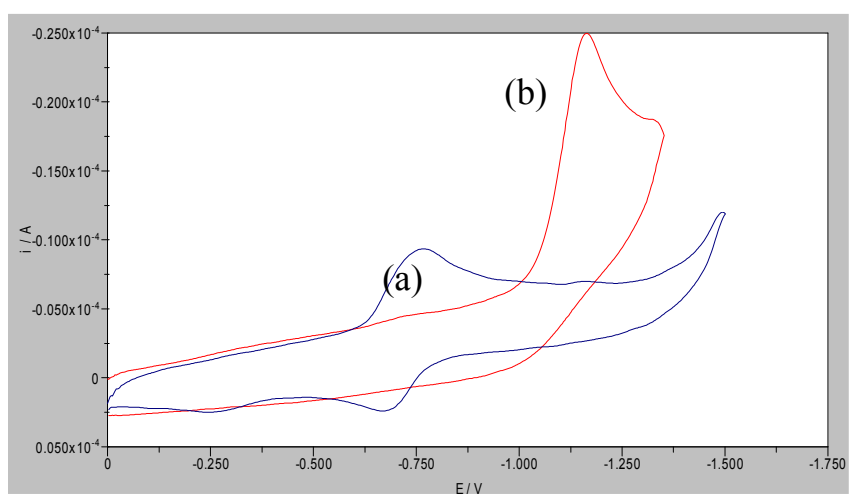

Figure 15. Cyclic voltammograms of direct reduction of cyanocobalamin (a) and dicofol (b).

The reduction of a $1.0 \times 10^{-3} \mathrm{M}$ solution of dicofol in presence of cyanocobalamin $\left(1.0 \times 10^{-4} \mathrm{M}\right)$ in acetonitrile-aqueous solution (1:1) is shown in figure 16 .

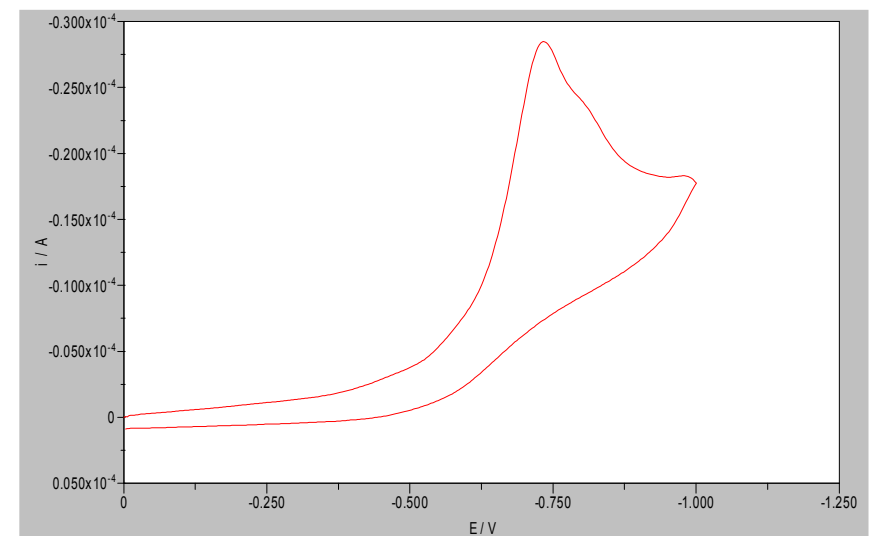

Figure 16. Cyclic voltammogram of $1.0 \times 10^{-3} \mathrm{M}$ dicofol in presence of $1 \times 10^{-4} \mathrm{M}$ cyanocobalamin at $0.01 \mathrm{~V} / \mathrm{s}$.

For comparison separate reductions of dicofol and cyanocobalamin have been overlaid (figure 17) .

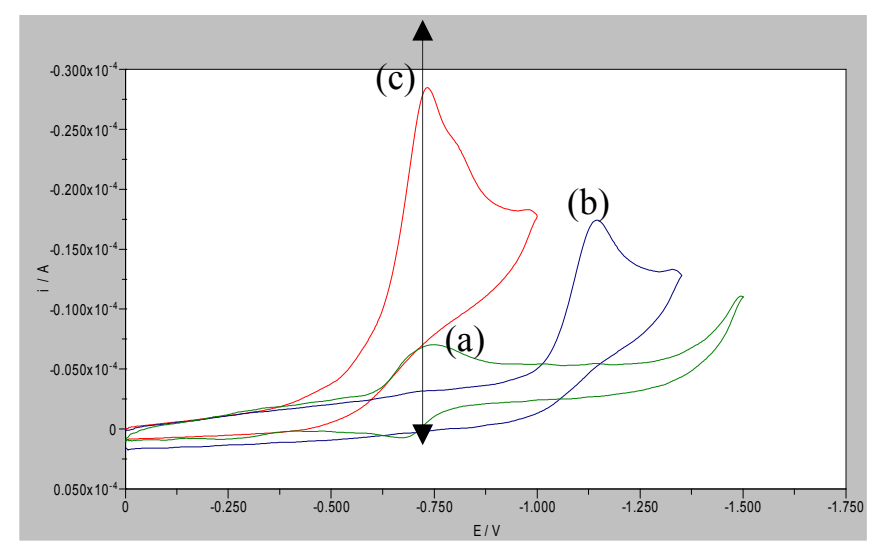

Figure 17. Cyclic voltammograms of 0.0001M cyanocobalamin alone (a), $0.001 \mathrm{M}$ dicofol alone (b) and 0.0001M cyanocobalamin with added 0.001M dicofol (c) in acetonitrile-water (1:1) at 0.01 V/s vs SCE.

A catalytic peak is observed at a potential approximately coinciding with the reduction peak potential of 
cyanocobalamin. On the reverse scan, the oxidation peak is absent. From the figure it can be seen that the catalytic peak current is more enhanced.

Here, electrons are supplied to cyanocobalamin by the cathode, which reduces the catalyst to its active form. The reduced catalyst transfers the electron to dicofol (acceptor). The reaction occurs at the electrode potential $\mathrm{E}^{\circ}$ at which the active form of the catalyst is produced. The absence of anodic peak is because of irreversibility of the reduction process. The product of reduction is unstable and none of it goes through oxidation. ([11].

Enhanced catalytic peak current could be explained by the electrochemical regeneration of a 'supernucleophile' intermediate, which in the case of cyanocobalamin, $\mathrm{Co}(\mathrm{III}) \mathrm{L}$ is through either:,

$$
\begin{aligned}
& \mathrm{Co}\left(\text { III) } \mathrm{L}+\mathrm{e}^{-} \rightleftharpoons \mathrm{Co}(\text { II) } \mathrm{L} ; \quad \mathrm{Co}(\mathrm{II}) \mathrm{L}+\mathrm{e}-\rightleftharpoons \mathrm{Co}(\mathrm{I}) \mathrm{L}\right. \\
& \mathrm{Or} \\
& \mathrm{Co}(\mathrm{III}) \mathrm{L}+2 \mathrm{e}^{-} \rightleftharpoons \mathrm{(I)} \rightleftharpoons
\end{aligned}
$$

$\mathrm{L}$ is the ligand. Based on the above observations, we suggest the mechanism shown in equation 2 for the catalytic reduction of dicofol. The reduced form of cyanocobalamin, $\mathrm{Co}(\mathrm{I})$, reacts with the organohalides $(\mathrm{RX})$ as shown below:

$$
\begin{aligned}
& \mathrm{RX}+\mathrm{Co}(\mathrm{I}) \mathrm{L} \longrightarrow \mathrm{R}-\mathrm{Co}(\mathrm{III}) \mathrm{L}+\mathrm{X}^{-} \ldots \ldots \ldots . .(3) \\
& \mathrm{R}-\mathrm{Co}(\mathrm{III}) \mathrm{L}+\mathrm{H}^{+}, 2 \mathrm{e}^{-} \longrightarrow \mathrm{R}^{-} \mathrm{CH}_{2}\left(\mathrm{CH}_{2}\right)_{\mathrm{n}}+\mathrm{Co}(\mathrm{I}) \mathrm{L}
\end{aligned}
$$

It is believed that the rate determining step is the attack by $\mathrm{Co}(\mathrm{I}) \mathrm{L}$ on the alkyl halide. The resulting carbon-cobalt bond can be cleaved by visible light, electrolysis, or by reducing agents to give carbon-centred radicals that can add onto activated carbon-carbon double bonds [30]. The different cathodic currents obtained in the presence and absence of catalyst at similar concentration of substrate and disappearance of anodic peak in presence of a substrate are two significant features in the electrocatalyzed reduction of dicofol.

The catalytic activity (lowering of potential) was quantized by: $\Delta \mathrm{E}_{\mathrm{p}}=\mathrm{E}_{\mathrm{p}}^{\mathrm{dc}}-\mathrm{E}_{\mathrm{p}}^{\mathrm{d}}$ where $\mathrm{E}_{\mathrm{p}}^{\mathrm{dc}}$ is reduction potential for dicofol in presence of cyanocobalamin and $E_{p}^{d}$ is reduction potential for dicofol alone. The electrocatalysed reduction of dicofol showed that the catalyst lowers the reduction potezsntial by $0.3963 \pm 0.008$ (for six scans) making the process energetically favoured. Electrical energy = EcellCtrans where Ecell is the cell potential measured in volts (V) and Ctrans is the cell current integrated over time and measured in coulombs (C); Ctrans can also be determined by multiplying the total number of electrons transferred (measured in moles) times Faraday's constant (F). Welectrical $=-\mathrm{nF} \cdot$ Ecell, or $\Delta \mathrm{G}=-\mathrm{nF} \cdot$ Ecell. In this case, direct reduction of dicofol is non-spontaneous process that requires $+22812.7 \mathrm{~J}$ $(228.123 \mathrm{kj})$ to drive the reaction.

Upon catalysis, Ecell shifted to more positive potential (potential of the catalyst). This reduced $\Delta \mathrm{G}$ to $151642.3 \mathrm{~J}$ ( $151.642 \mathrm{kj})$. It is about $1 \frac{1}{2}$ times lowered. These values of $\Delta \mathrm{G}$ are reported for the first time in this research. The decrease in $\Delta \mathrm{G}$ implies that electrocatalysis is more kinetically favourable compared to direct electrochemical activation of carbon-halogen bonds.

The current efficiency was also quantified by:

$$
\Delta i_{p}=\frac{i_{p}^{d c}}{i_{p}^{c}}
$$

where $i_{p}^{c}$ is the peak current for cyanocobalamin alone and $i_{p}^{d c}$ is the peak current for dicofol in presence of cyanocobalamin. The current efficiency was 3.685 times and decreased with increase in scan rate. The reduction peak current (ip) for electrocatalysed reduction was not proportional to square root of scan rate $\mathrm{v}^{1 / 2}$ implying that electrocatalysis is not a diffusion controlled process (figure 18).

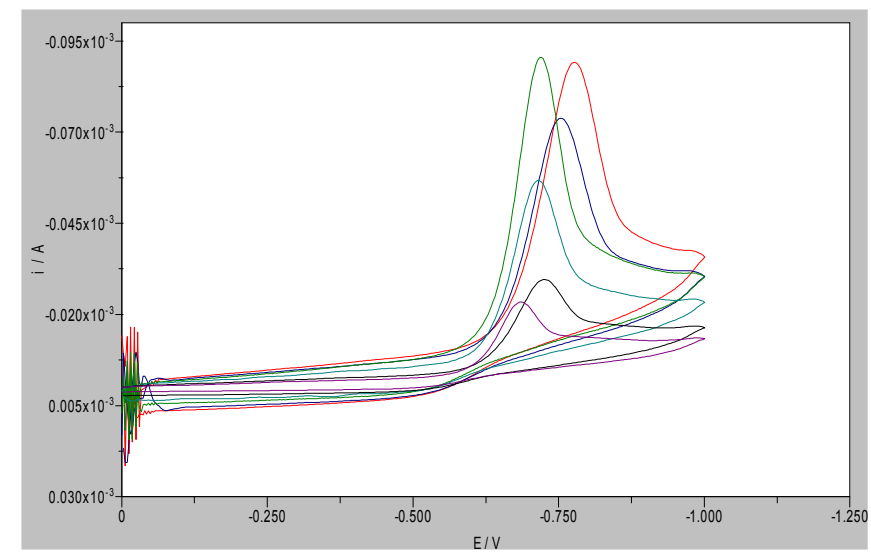

Figure 18. Cyclic voltammograms of dicofol in presence of cyanocobalamin at different scan rate (between $0.01 \mathrm{~V} / \mathrm{s}$ and $0.1 \mathrm{~V} / \mathrm{s}$ ).

\section{Conclusion}

May be the best interpretation of electrocatalysis is due to A. J. Appleby as an electrochemical reaction with an adsorbed species, either as reactant and/or product, which can change the kinetics of the reaction and in some cases also the mechanism. Cyanocobalamin is a suitable catalyst for decomposition of dicofol. Electrical energy required to drive catalytic reduction of dicofol in presence of cyanocobalamin is much lower than that in direct reduction. This makes electrocatalytic reduction more thermodynamically favourable. The peak shape and the linear relationship of the reductive and reverse oxidative current vs. electrode potential curve (I-E) in the voltammograms for ferricyanide, cyanocobalamin and dicofol is typical of an electrode reaction in which the rate is governed by diffusion of the electroactive species to the electrode surface. A significant difference in cathodic peak currents obtained in the presence and absence of catalyst was observed. 


\section{Recommendation}

Electrocatalysis is a special field in electrochemistry that has gained a special growth after the late eighties due to the application of new hybrid techniques. However, most of the applications have run for academic purposes but not for technical uses in the industry. Industrial electrocatalytic processes have only been presented in the literature from the chemical engineering point of view. This research would recommend that the new concepts of electro-catalysis be made available for industrial electrochemical processes. Emphasis should be put on alternative methods of pest control such as biological control, crop rotation, intergrated crop management which establishes chemical use on a need basis only. This research would recommend organic farming that would minimize exposure to pesticide residues. Even though some organic foods contain significantly less amounts of pesticides than non-organically produced products, they still contain certain amounts of residue levels that are persistent in the environment. The methods of organic farming prohibit the use of many pesticides. In addition to choosing to buy organic produce, there are certain measures that can be taken to minimize exposure to harmful residues: washing vegetables may help remove chemical residues, peeling fruits and vegetables that have known high levels of pesticide residues, and growing your own essential produce. This study also recommends, further work on more of organohalide pollutants using other solvent media other than organic solvents. It recommends further work in order to identify the products of decomposition of dicofol.

References and further reading may be available for this article. To view references and further reading you must purchase this article.

\section{References}

[1] A. Ozcan., (2010), "Degradation Of Hazardous Organic Compounds By Using Electro-Fenton Technology". Doctoral Thesis "University of Paris-Est"- France and "Anadolu University"- Turkey

[2] U.S. Environmental Protection Agency, (1987), "Health Advisory: Chlordane. Office of Drinking Water, Washington, DC.

[3] Sazova, Y., (2004), "Investigation of Dicofol and Endosulfan pesticide levels in Tahtali dam water or drinking water", Thesis of Master, Đzmir Institute of Technology, Đzmir, Turkey.

[4] MAFF, (1996), "Review of dicofol. London, Ministry of Agriculture, Fisheries and Food, September.

[5] WHO, (1992), "The WHO recommended classification of pesticides by hazard and guidelines to classification 1992-1993", Geneva, World Health Organization, nternational Programme on Chemical Safety (WHO/PCS/92.14).

[6] USEPA, (2006), "PBT profiler methodology. United States Environmental Protection Agency, Office of Pollution Prevention and Toxics" (http://www.pbtprofiler.net/methodology.asp).
[7] Roberts, E.M., English, P.B., Grether, J.K., Windham, G.C., Somberg L., Wolff, C., (2007), "Maternal residence near agricultural pesticide applications and autism spectrum disorders among children in the California Central Valley" (PDF). Environmental Health.

[8] Budnikova, Yu. H., Kafiyatullina, A. G., Kargin Yu. M., and Sinyashin, O. G., (2002), "Electrocatalytic reduction of organic halides with cobalt bipyridine complexes": Russian Chemical Bulletin, 51, No.9: 1702-1708. Catalyzed by Hydrophobic Vitamin B12 Using Sacrificial Electrode" Chem. Lett 38, 26

[9] Abdirisak, A. I., Giacomo, B., Luigi, F., Manuela, R., Patrizia, R. M., Armando, G., ( 2009), " Electrocatalysis and electron transfer mechanisms in the reduction of organic halides at Ag": Journal of Applied Electrochemistry 39:2217-2225

[10] Manahan, S. E., (2010), "Toxicological Chemistry and Biochemistry". (3 ed). Taylor and Francis Group, LLC.

[11] Kamau, G .N., Rusling, J.F. (1992), "Rate Enhanced and Control in Electrochemical Catalysis using a Bicontinous microemulsion”: Langmuir 8 No.4: 1042-1044.

[12] Rusling, J.F. (1991), "Controlling Electrochemical Catalysis with Surfactant Microstructures": Ace. Chem. Res 24, No. 3: $75-81$.

[13] David, D., (1971), "Preparation of the Reduced Forms of Vitamin B12 and of Some Analogs of the Vitamin B12 Coenzyme Containing a Cobalt-Carbon Bond. D.B. McCormick and L.D. Wright, Eds.;Vol. XVIII:34-54.

[14] Savient, J.M., Costa, G., (1979), "Application of Electrochemical Techniques to Study of Chemical Reactions". Ed. Pletcher, T.C. Marcel Dekker, New York.

[15] Kissinger, P.,William, R. H., (199, “ Laboratory Techniques in Electroanalytical Chemistry". Second Edition. Revised and Expanded CRC.

[16] Hisaeda, Y. Ling, P., and Shimakoshi, H., (2009), "Electrochemical Methyl-transfer Reaction.

[17] Rashid, O. Kadara, Norman Jenkinson, Craig E. Banks, (2009), "Faculty of Science and Engineering, School of Biology, Chemistry and Health Science, Division of Chemistry and Materials, Manchester Metropolitan University, Chester Street, Manchester M1 5GD, Lancs, UK

[18] Steven, P., (2000), "Cyclic Voltammetry of Hexachloroiridate(IV): An Alternative to the Electrochemical" Study of the Ferricyanide Ion. The Chemical Educator, Vol. 5, No. 5, Springer-Verlag New York, Inc.

[19] Kadish, K.M., Ding, J.O., and Malinski, T., (1984), "Resistance of non-aqueous solvent system containing tetralkylammonia salts. evaluation of heterogeneous electron transfer rate constants for the ferrocene/ferrocenium couple". Analytical Chemistry. 56, 1741-1744.

[20] Nicholas, R.S., (1965), "Theory and Application of Cyclic voltammetry for measurement of electrode reaction kinetics". Analytical Chemistry. 37 1351-1355.

[21] Rao, S.P., Singh, S.R. Bandakavi, S.R., (1978), "Formal Redox Potentials of ferricyanide ferrocyanide Couple in certain non-aqueous water mixtures. Department of Chemistry". University of Jodhpur, Jodhpur, Rajasthan. 
[22] Kamau, G.N., Willis, W.S., and Rusling, J.F., (1985), "Electrochemical and electroscopic studies of highly polished glassy carbon electrodes". Anal. chem. Vol. 57, 545-551.

[23] Yang, Rongwu; Liu, Xinjian; Zhu, Zhiqiang; Liu, Shanli; Li, Genxi, (2006), "Enhanced Electron Transfer and Catalytic Activity of Cyanocobalamin with $\beta$-Cyclodextrin" Sensor Letters, 4, No 4: 416-418

[24] D. Lexa, J.M. Savèant and J. Zickler. J. Am. Chem. Soc. 102 (1980), p. 2654.

[25] Vilakazi, S. L. and and Nyokong, T., (2000), "Electrocatalytic properties of vitamin B12 towards oxidation and reduction of Nitric Oxide" : Electrochimica Acta, 46, Issue 4: 453-461

[26] Lagunas, M.C., Silvester, Debbie S. Aldous, Leigh and Compton, Richard G. (2006), "The Electrochemistry of Vitamin B12 in Ionic Liquids and Its Use in the Electrocatalytic Reduction of Vicinal Dibromoalkanes"Electroanalysis 18, No.22: $2263-2268$.

[27] Qiu, Q. and Dong, S. (1993), "Rapid determination of kinetic parameters for the electrocatalytic reduction of dioxygen by vitamin B12 adsorbed on glassy carbon electrode" Electrochimica Acta, 38, Issue 15: 2297-2303.

[28] Bard, A. J., Faulkner, L. R. (2000), "Electrochemical Methods: Fundamentals and Applications". (2 ed). New York: Wiley.

[29] Kissinger, P.T., Heineman, W.R., (1983), "Cyclic Voltammetry":Journal of Chemical Education, 60, 702

[30] Trevor J. D.,Craig E. B., Bharathi, N., Rusling, J. F., Robert, R. France, Jay D. W. and Richard, G. C., (2002), "Surfactant-free emulsion electrosynthesis via power ultrasound: electrocatalytic formation of carbon-carbon bonds". Oxford University. Uk

[31] Manisankar, P.; Viswanathan, S.; Mercy Pusphalatha, A.; Rani, C., (2005), Anal. Chim. Acta, 528, 157.
[32] Andrieux, C.P; Sav'eant, J.M; Zann, D (1984). Nouv J Chim 8:107

\section{Biography}

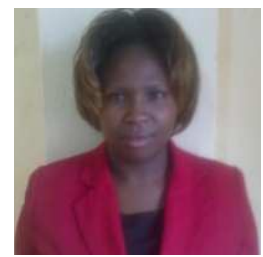

Wanjau T. Wangui is a $\mathrm{PhD}$ candidate at Egerton University and currently working with Kisii University as a Lecturer of Chemistry in the faculty of health Sciences.

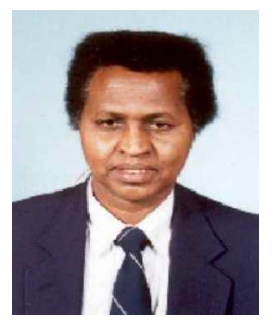

Prof. G.N. Kamau is an experienced Professor of Chemistry with a bias in Electrochemistry; Department of Chemistry, University of Nairobi. He has been an Educator, Administrator, involved in Laboratory Management and an Environmentalist.

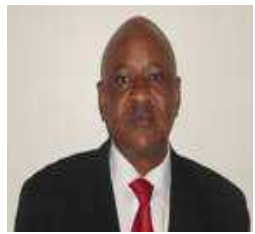

Prof. Mwaniki S. Ngari is an experienced Professor of Chemistry with a bias in Analytical Chemistry. He has been a long serving Professor and an administrator of Egerton University and as Deputy Vice Chancellor (Academic Affairs) Kisii University.

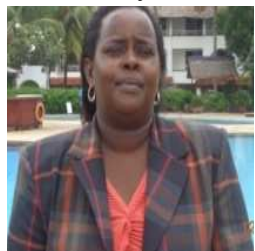

Catherine Njambi Muya is a $\mathrm{PhD}$ candidate at Nairobi University and currently working with the technical University of Kenya as a Lecturer of Chemistry in the faculty of Environmental Sciences. 